\title{
LA CAPILLA DE MÚSICA DE LA COLEGIAL DE SAN NICOLÁS DE ALICANTE DURANTE EL SIGLO XVIII
}

\section{Andrés PALENCIA SOLIVERES}

Universidad de Alicante

Las manifestaciones musicales y su organización institucional a lo largo de los siglos XVI al XVIII son aspectos poco conocidos de la cultura alicantina. Analizar el alcance y la proyección social que tuvo el desarrollo de un centro artístico-cultural a lo largo de la Edad Moderna, y de forma más particular durante el siglo XVIII, representa una tesela más en la reconstrucción del calado que tuvieron las diversas formas de la cultura en el entramado social de una ciudad como Alicante. De la misma manera, las manifestaciones festivas de carácter religioso y profano, en las que se halla presente de una forma activa el componente musical, han de ser contempladas para contribuir a completar el panorama artístico-cultural de aquellos siglos ${ }^{i}$.

La música no sólo ha tenido una manifestación sacra y solemne, ni ha sido producida y dirigida a las élites sociales, sino que también ha estado siempre ligada a las manifestaciones populares formando parte de su bagaje cultural.

La actividad musical desplegada en Alicante durante los siglos XVI al XVIII se centró en dos grandes líneas de actuación. La primera correspondiente a la música religiosa, cuyos centros fueron las capillas de música de la parroquía de Santa María y de la colegial de San Nicolás. La segunda, englobaría la música profana, hecha fuera del templo, y que podriamos calificar de civil, distinguiendo entre las formas cortesanas o cultas, y aquellas que se proyectan en un ambiente popular, que aparecen con frecuencia cargadas con una simbología de crítica social y protesta, siendo ajenas, por tanto, a la cultura oficial.

Durante la Edad Moderna, la Monarquía y la Iglesia impulsaron y mantuvieron el patronazgo de la creación nisusical. Bajo la esfera del poder civil y 
religioso se celebraron las principales conmemoraciones de la ciudad: fiestas locales, acontecimientos extraordinarios, como coronaciones, bodas $y$ visitas reales. celebraciones de victorias militares, etc. Pero, fueron las capillas de música las que canalizaron la mayor parte de la labor artística a lo largo de las etapas del Barroco y del Clasicismo, movimientos que dejaron huella testimonial en la sociedad alicantina.

En concreto, la capilla de la colegial de San Nicolás se convirtió en un centro productor de cultura en cuanto fue protagonista activo en representaciones sacras o cívicas, en las que la música interpretada pretendía dar solemnidad a los oficios religiosos alcanzando un carácter espectacular, o completar las formas exteriores de representación del poder en las celebraciones oficiales. Sus músicos participaban también en las manifestaciones festivas de la ciudad, convirtiéndose en agentes activos de los festejos populares.

Será en 1600, año de la erección en colegial de San Nicolás, cuando empiece a funcionar una capilla de músicos bajo los auspicios del cabildo municipal. Creada al servicio de la iglesia, su misión fue la de interpretar la música de la liturgia, por lo que el repertorio era exclusivamente religioso. Acompañaba todos los actos y funciones del calendario festivo y del culto diario. Además, era pieza imprescindible en la celebración de la Navidad y de la Semana Santa, para las que se componían villlancicos y otros cánticos similares.

Dirigida por un maestro, la capilla de música estaba compuesta por un grupo de cantores e instrumentistas, ministriles y niños del coro, cuya situación y gajes variaron a lo largo del tiempo.

El conocimiento y funcionamiento de los aspectos internos -fundación, estatutos, organización y composición, forma de ingreso, creación de las plazas, estipendios, etc; el calendario de actuaciones, los instrumentos y el órgano de la iglesia y, en particular, las relaciones entre cabildo eclesiástico y municipal, forman elementos esenciales a la hora de recomponer el entramado de la vida musical de la capilla.

\section{Creación de una capilla de música}

Pocos son los datos que poseemos acerca de la actividad realizada por músicos de la capilla en las funciones públicas organizadas por el cabildo de la ciudad anteriores al siglo XVII, pero gracias a las distintas crónicas locales conocemos la participación de éstos en algunos actos destacados bajo el reinado de Felipe II y Felipe III ${ }^{2}$. Tras ser proclamada colegial la iglesia de San Nicolás ${ }^{3}$ cobra el protagonismo musical de la ciudad. Las exigencias del culto impusieron la necesidad de dotar una capilla de música acorde con otros templos de su categoria. 
Mosén Nicolás Salinas (h. 1600) quedó al frente de la recién formada capilla a cuyas órdenes estaba un grupo de instrumentistas.

La dotación corrió a cargo de la ciudad para lo cual dispuso una cantidad anual, y se reservaba el derecho de nombrar al maestro y demás componentes de la misma. Este hecho derivó en lo sucesivo en no pocos conflictos con el cabildo eclesiástico, puesto que el patronato de la capilla lo ostentaba sólo el municipio ${ }^{4}$.

A lo largo del siglo XVII la capilla ofreció un servicio esencial en las funciones públicas, pero las noticias de que disponemos para este periodo, permiten vislumbrar una andadura nada fácil, al menos hasta que, en 1669, aparecen los nuevos estatutos concedidos por Carlos II, en los cuales quedaba regulado el capítulo de la misica, con los salarios correspondientes de sus integrantes 5 .

El acceso al trono de Felipe V (1700-1746), propició la reorganización de la capilla de música, en 1714 , al crearse nuevas plazas con renovadas dotaciones, siendo puesta bajo la dirección del maestro mosén Isidro Escorihuela (1690-1716).

La configuración básica de la capilla quedó, desde entonces, como sigue ${ }^{6}$ :

\begin{tabular}{|c|c|c|}
\hline$\underline{\text { PLAZA }}$ & NOMBRE & $\underline{\text { SALARI }}$ \\
\hline Maestro & m. Isidro Escorihuela (1690-1716) & $60 \mathrm{lbs}$. \\
\hline org./arpista & m. Tomás García (1716-1723) & 80 \\
\hline violín $1^{\circ}$ & Vicente Oltra $\quad(1714-1723)$ & 60 \\
\hline violín $2^{\circ}$ & Pascual López (d. 1720) & 60 \\
\hline corneta & Francisco Romero & \\
\hline bajón $1^{\circ}$ & Manuel Carratalá (1714-1723) & 80 \\
\hline bajón $2^{\circ}$ & Alonso Ximénez (1714-1723) & 40 \\
\hline tenor & m. José Carrasco (1723) & 50 \\
\hline contralto & Bartolomé Falomir (1719-1723) & 50 \\
\hline \multirow[t]{2}{*}{ tiple $1^{\circ}$} & Justino Perochi (1718) & 100 \\
\hline & Francisco Vidal & \\
\hline \multirow[t]{2}{*}{ tiple $2^{\circ}$} & Sebastián Alduchi (1716) & 100 \\
\hline & Manuel Carratalá(hijo) & 25 \\
\hline
\end{tabular}

La capilla continuó su labor durante todo el siglo como una formación estable de profesionales al servicio de los cabildos eclesiástico y municipal. 


\section{Organización y funcionamiento}

El mecenazgo de los cabildos posibilitó la existencia de un número estable de plazas para músicos profesionales. Sin embargo, la importancia de las sedes eclesiásticas, y los distintos emolumentos con que se retribuían, favorecieron la movilidad geográfica de los miembros de las capillas. Aunque sin poder hablar en sentido estricto de la existencia de un cursus honorum, las biografías de los maestros y músicos más cualificados permite establecer una jerarquía reconocida a la hora de valorar las plazas en las diferentes capillas.

La capilla de música se puede definir, en el caso alicantino, como un grupo pequeño de cantores e instrumentistas que, bajo la dirección y enseñanzas del maestro, interpreta la música que acompaña a los actos litúrgicos que se celebran en la iglesia ${ }^{7}$.

La figura del maestro destacaba por encima de todos, pues a él correspondía la dirección técnica y artística de la capilla. Maestros y músicos tenían la responsabilidad de cumplir con un calendario establecido de actuaciones en las funciones de culto ordinarias o extraordinarias, bien en la colegial, bien fuera de ella, de acuerdo con las disposiciones del cabildo.

La mayor parte de los instrumentistas y los músicos de voz se formaban en las capillas y en los coros de las iglesias bajo la supervisión de los maestros. Otros, en cambio, se preparaban en colegios y seminarios con el fin de superar las pruebas de ingreso, generalmente por medio de una oposición pública, aunque, en ocasiones, los pretendientes se eligieron sin examen, justificándose entonces la "necesidad urgente" de cubrir alguna plaza vacante.

La composición de la capilla durante el período 1600-1869 quedó establecida de la siguiente manera ${ }^{8}$ :

\section{MAESTRO}

CANTORES
tiple $1^{\circ}$ y $2^{\circ}$
tenor $1^{\circ}$ y $2^{\circ}$
contralto
bajo
GRUPO DE VIENTO
bajón $1^{\circ}$ y $2^{\circ}$
corneta
INFANTILLO DEL CORO

INSTRUMENTISTAS

arpa/órgano

GRUPO DE CUERDA

violin $1^{\circ}$

violín $2^{\circ}$

violonchelo

contrabajo

MINISTRILES

chirimías y flautas

sacabuig/trombón

orlos y cornetas 
Para aspirar al ingreso en la capilla de música, el cabildo municipal exigía la presentación de certificados e informes que acreditaran el buen desempeño de su oficio en el caso de contar con la experiencia previa, pero también era una exigencia añadida que presentaran declaraciones que garantizasen una buena conducta personal. Testimonios ambos que no les eximian de demostrar su habilidad en el manejo de los instrumentos.

Los candidatos seleccionados pasaban a formar parte de la plantilla fija de la capilla, cuya reglamentación detallaba minuciosamente sus obligaciones, y entre ellas que : "... han de asistir a todas las fiestas votadas por la ilustre ciudad, sin pretender otra paga que la de los salarios, exceptuando las porciones prevenidas por los reales estatutos y por las fiestas y asistencias extraordinarias ${ }^{\prime \prime}$.

El viejo sistema de nombramientos había cambiado desde comienzos del siglo XVIII al quedar el patronazgo de la capilla bajo la jurisdicción de los regidores municipales, quienes organizaban la celebración de festejos y el funcionamiento de la capilla de música. La votación secreta de "habas blancas y negras" dejó paso a la convocatoria pública previa publicación de edictos en otras iglesias en los que se especificaban las condiciones del cargo, los salarios y las disposiciones que deberían cumplir los candidatos.

Los pretendientes al empleo eran examinados por el maestro titular y por los comisarios, en representación éstos de los respectivos cabildos eclesiástico y muncipal de la ciudad. Una vez examinados, el maestro presentaba al cabildo municipal un informe con los resultados de las pruebas. Posteriormente, una resolución capitular confería o denegaba la plaza y asignaba el salario anual correspondiente. Sólo restaba entonces mandar notificación al cabildo eclesiástico.

Como principal beneficiario de la capilla, el cabildo municipal se esforzó en encontrar personas cualificadas para desempeñar su oficio. Una tarea que no siempre resultaba fácil, no sólo por las dificultades de elegir los músicos más apropiados, sino por los conflictos que surgieron entre las autoridades muncipales y las eclesiásticas en relación a las competencias que tenían sobre la capilla de música.

Desde la creación de la capilla, cl cabildo eclesiástico intervino activamente en la dotación de las plazas, si bien la ciudad gozaba del derecho de Patronazgo, utilizado muchas veces para imponer su voluntad frente a los deseos de la iglesia que, en la práctica, jugó un papel meramente consultivo en los asuntos de la capilla. Viravens Pastor, recogía en su Crónica de la muy Ilustre y siempre Fiel Ciudad de Alicante, un sonado lance que sobrevino cuando el Obispo de Orihuela decidió que la capilla participase, el 30 de marzo de 1600 , en los actos de consagración de los Santos Óleos que había de celebrarse en la iglesia de San Nicolás, en vez de hacerlo en la iglesia de Santa Maria, entonces iglesia mayor, y a la que solía acudir el cabildo municipal. Las autóridades municipales de la ciudad amenazaron al entonces 
maestro, mosén Salinas, con meterle en prisión si acudía a la función preparada en la iglesia de San Nicolás. El prelado de la diócesis de Orihuela replicó acto seguido con la pena de excomunión para algunos de los iurats de la ciudad, que sólo entonces se doblegaron a autorizar que los músicos de la capilla acudiesen al oficio conforme a las disposiciones del Obispo ${ }^{10}$. Posteriormente, una vez constituida la iglesia de San Nicolás como colegial, los conflictos no dejaron tampoco de producirse, aunque sin llegar al grado de enfrentamiento del caso al que acabamos de aludir. Así, por ejemplo, otro de las disputas que protagonizaron ambos cabildos surgió con ocasión del nombramiento del maestro López Ceballos en 1781. En esta ocasión, otro opositor que no obtuvo la plaza, Vicente Torres, trató de impugnar la resolución del cabildo municipal alicantino protestanto de diversas irrgularidades ante el cabildo eclesiástico y ante el Consejo de Castilla. El recurso prosperó inicialmente, pero, una vez en su puesto, las críticas atizadas contra él le determinaron a abandonar finalmente su cargo, prevaleciendo también en esta ocasión el criterio de las autoridades muncipales ${ }^{11}$.

Por otra parte, también surgieron problemas internos entre los miembros de la capilla. La insufiencia de los salarios, las frecuentes ausencias a las funciones de tabla, la obligación de tocar otros instrumentos cuando había ausencias o vacantes, las reclamaciones ante las resoluciones capitulares cuando se cubrían las plazas desocupadas, fueron los conflictos más corrientes que encotramos en la documentación sobre la capilla alicantina.

Durante el nuevo magisterio de Agustín Iranzo (1789-1804) se hubieron de afrontar varios desórdenes, ausencias y faltas graves de algunos músicos, que repercutian negativamente en en funcinamiento normal de la capilla. En un intento de poner fín a los conflictos más cotidianos se volvió a perfilar el Arancel de fiestas a las que, por obligación, debian acudir los componentes de la capilla ${ }^{12}$. Igualmente se arbitraron una serie de medidas disciplinarias, que iban desde meros avisos hasta multas y castigos según la gravedad de la falta cometida, y que procuraron mantener la organización conforme había sido establecida en los estatutos.

\section{El maestro y los músicos de la capilla}

El maestro era la máxima autoridad en la jerarquía de la capilla. Trabajaba bajo las órdenes directas del cabildo y vigilaba su buen funcionamiento. $\mathrm{Al}$ magisterio se accedía tras superar unas pruebas de oposición que solían durar tres días, y que entrañaban serias dificultades ${ }^{13}$. En las pruebas debían demostrar un alto grado de conocimientos musicales, de composición, de enseñanza y de dirección ${ }^{14}$. Entre las obligaciones de los opositories figuraba la de componer obras -a varias voces- en veinticuatro y cuarenta y ocho horas; componer villancicos con instrumentos; realizar ejercicios de contrapunto y dirigir actuaciones de la capilla con partituras desconocidas de anemano y sin determinar el compás ${ }^{15}$. 
El procedimiento administrativo para cubrir las vacantes seguía las pautas descritas anteriormente: publicación de edictos y concurso público. Excepcionalmente, el cabildo municipal hizo prevaler su criterio haciendo uso del derecho de Patronato sobre la capilla. Condición habitual en los maestros de capilla, aunque no indispensable, era la de ser clérigo, aunque también encontramos algunos seglares al frente de aquélla ${ }^{i 6}$.

Una vez conferida la plaza el maestro adquiría una serie de obligaciones:

1.- Dirigir la música de canto y órgano; regir el fascitol en las funciones acordadas con el cabildo municipal y la iglesia.

2.- Componer los villancicos para el Corpus, Navidad y festividad de San Nicolás; componer también lamentaciones y obras de órgano -tanto la letra como la música-, así como funciones de réquiem a toda orquesta, Te Deum y misa a cuatro voces.

3.- Enseñar y regir el coro en las festividades, dentro y fuera de la iglesia.

4.- Enseñar solfeo, contrapunto, órgano, canto y composición a los que estaban bajo su cuidado y formación, como los niños ministriles, los del coro, los acólitos y demás cantores, includos los dos tiples, a quienes, estatutariamente, el maestro tenía la obligación de "alimentar, vestir y enseñar"17, y a cualquiera que, teniendo las cualidades exigidas, se le ofreciera como discípulo ${ }^{18}$.

A cargo del maestro quedaba también el Archivo de la capilla, quien debía Ilevar "la bolsa" y repartir "los papeles". Le correspondía también dar aviso al cabildo de las faltas que notase en la capilla y procurar que todos los músicos asistieran a las funciones "en traje decente y negro"19.

Así pues, las composición, dirección de capilla, las clases, los ensayos de la capilla, los tribunales de oposición y la asistencia a las celebraciones extraordinarias dentro y fuera de la ciudad venían a representar el grueso de las responsabilidades de los maestros.

Los miembros de la capilla no podían ausentarse ni actuar en otros lugares, días ni horas fuera de lo prescrito sin la autorización pertinente del cabildo, pues, de lo contrario, eran sancionados. Uno de los motivos de ausencia más frecuentes fue el de enfermedad. La petición de licencia iba acompañada del consiguiente informe médico con lo que se concedían los permisos en resolución capitular. Es muy significativo el caso de Vicente Torres Escalante, maestro y presbítero, quien tuvo que abandonar la capilla por estar enfermo "del accidente de hipocondría y pasión de cinimos y diabetes, con calenturas agudas, (...) con una resecación del humor y fluxión de orina (...) contraida por los contínuos insultos que ha sufrido. Los 
informes médicos alegaron que estaba "escasisimo de carnes, decadente de fuerzas $e$ inapetente de tomar alimento alguno. Por ello no está firme (...) ni aún para rezar". El maestro salió de la ciudad en busca de aires más saludables, pero no llegó a recuperarse y renunció a la plaza ${ }^{20}$.

Una primera relación de los maestros que estuvieron al frente de la capilla alicantina fue recogida por Villar Miralles a finales del siglo XIX, si bien una revisión exhaustiva de los cabildos municipales nos ha permitido ampliar los datos disponibles:

\section{RELACIÓN DE MAESTROS DE LA CAPILLA DE MÚSICA $(1600-1804)^{28}$}

\author{
Mosén Nicolás Salinas \\ Mosén Juan Bautista de Lillo \\ Mosén Isidro Escorihuela \\ Mosén Manuel Comeres \\ Mosén Gabriel Aznar \\ Agustín Iranzo Herrero \\ Vicente Torres y Escalante \\ Mosén Bernardo Chorro (regente) \\ Agustín Iranzo Herrero
}

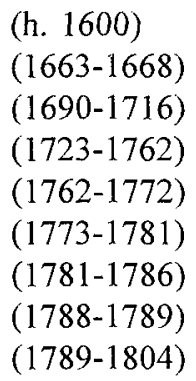

(h. 1600$)$

(1663-1668)

(1789-1804)

Al igual que otras colegiatas españolas, la de San Nicolás atravesó momentos de mayor o menor brillantez dependiendo en gran parte de la talla de los diferentes maestros, y del saber hacer de los músicos y cantores que tuvieron a su servicio. Hablar de la capilla en un momento determinado es hablar fundamentalmente del trabajo desplegado por el maestro en ese período. Los intentos de prefeccionar el funcionamiento de la capilla fueron constantes, y se abordaron varios planes de remodelación interna para la mejora y adaptación de la capilla a los nuevos tiempos que impuso el Clasicismo, así como para encontrar más recursos económicos.

El músico instrumentista, el de voz, el infantillo del coro y la figura del organista y arpista forman el grupo de profesionales de la capilla de música que interpretaban la música. El número de estas plazas fue establecido en doce a lo largo del siglo XVIII, aunque, de hecho, la composicón efectiva varió entre once y trece. De ellas, cuatro eran para instrumentistas:

- Un organista/arpista.

- Dos violinistas.

- Un corneta.

- Un bajonista (o dos).

- Cuatro ministriles (bajo tutela del maestro). 
El resto de las plazas correspondía a los músicos de voz: dos de tiple, una de contralto, dos de tenor y una de bajo.

Al igual que el maestro, el músico tenía que superar unas oposiciones públicas para acceder a la plaza que ratificaría el cabildo eclesiástico. Condición esencial, al igual que en el caso anterior, era que los candidatos llevaran una vida decorosa y observasen buenas costumbres. Además, debian demostrar su habilidad y destreza en el manejo de los instrumentos correspondientes. Era preferible que perteneciesen al sacerdocio, pues de lo contrario, era habitual que el cabildo eclesiástico pusiera reparos a la hora de dar su conformidad para cubrir la plaza ${ }^{22}$.

En cuanto al capítulo de las obligaciones, los músicos contraían una serie de deberes que debían cumplir, so pena de recibir sanciones económicas o, en casos extremos, siendo castigados con la pérdia del empleo o la cárcel.

Las principales obligaciones del personal de la capilla pueden sintetizarse en las siguientes:

1.- Acudir a las funciones de tabla y siempre que lo estimasen los respectivos cabildos.

2.- Asistir a los ensayos generales de la capilla en la colegial.

3.- Recibir clases particulares de los maestros, y a su vez enseñar a los niños que quisieran aprender los diferentes instrumentos.

4.- Anunciar previamente de sus ausencias al cabildo, por el "detrimento que causa al culto divino".

Fue bajo la dirección del maestro Agustín Iranzo cuando la capilla de música alicantina alcanzó el mejor momento artístico, tanto por la calidad y número de los músicos, como por las obras interpretadas.

COMPOSICIÓN DE LA CAPILLA DE MÚSICA (1773-1781)

\begin{tabular}{llc}
\hline maestro & Agustín Iranzo Herrero & $100 \mathrm{lbs}$. \\
arpista/organista & Tomás Jover & 90 \\
violín $1^{\circ}$ & Antonio Ximénez & 75 \\
violín $2^{\circ}$ & Mosén José Rocafort & 60 \\
bajón $1^{\circ}$ & Gregorio Brufal & 60 \\
bajón $2^{\circ}$ & Miguel Oltra & 35 \\
corneta & José Monerris & 38 \\
bajo de voz & Damián Quevedo & 36 \\
tenor & Mosén José Soler & 60 \\
contralto & Mosén Bernardo Chorro & 60 \\
sochantre & Juan Eximeno & 30 \\
tiple $1^{\circ}$ & Ramón Bosch/Andrés Reus & 50 \\
tiple 2 & José Sempere/Fco. Molina
\end{tabular}




\section{El calendario de actuaciones}

La música que se interpretaba en San Nicolás contribuía a engrandecer la liturgia. Era difícil concebir la celebración de la misa, el día de Reyes, la Páscua, la Asunción o la Navidad sin el acompañamiento musical. Todas las funciones de la capilla estaban programadas en un calendario de regla que contenía además otras funciones extraordinarias ${ }^{23}$. No obstante, cabria distinguir entre las funciones de carácter religioso, organizadas por el cabildo dentro y fuera de la colegial, y las celebraciones extraordinarias de carácter profano o civil a las que se les daba mayor relevancia, aunque mantuviesen también un componente religioso. Enamadas del poder civil y religioso, las fiestas públicas fueron espectáculos dirigidos al pueblo en general con un alarde de lujo y ostentación exterior ${ }^{24}$. Entre las festividades más destacadas cabe señalar las del Santo Patrón, las de la Virgen, las de los Santos, traslaciones de reliquias, nombramientos de obispos y alto clero, fundación y consagración de iglesias o las honras fúnebres de reyes y altos personajes civiles y eclesiásticos. A éstas hay que añadir el conjunto de celebraciones organizadas por las Cofradías, las rogativas a la Santa Faz y las festividades de las pequeñas comunidades cercanas, que eran asistidas por la ciudad, y que, en conjunto, daban el tono del panorama musical alicantino.

\section{Las cuentas}

La capilla de música tenía asignada una cantidad fija anual señalada por los estatutos. La principal fuente de ingresos ordinarios provenía de las Arcas municipales de Propios y Arbitrios. Se libraban por tercias anticipadas como a los componetes de la capilla al igual que a otros asalariados de la ciudad. Sin embargo, en situaciones críticas, fue del producto de las fábricas de las iglesias, de donde se pagaron, algunas veces en especie como último recurso, los sueldos del maestro y músicos. La situación se normalizó desde comienzos del siglo XVIII, pues a partir de entonces los pagos se realizaron habitualmente en metálico.

Los salarios fijados estatutariamente a comienzos del siglo XVIII no escaparon, como tantos otros, a los efectos de la inflación y el alza de precios. Así, desde 1746 las reclamaciones de los miembros de la capilla ante la insuficiencia de sus salarios, les llevaron a recurrir en diversas ocasiones, ya en última instancia, al cabildo eclesiástico para que se aviniera a satisfacer algunas cantidades económicas complementarias que les sacaran de sus agobiantes apuros.

Entre 1767-71 el cabildo municipal asignó 9.803 libras y 10 maravedíes de vellón para la dotación anual de la capilla ${ }^{25}$. En 1787 , como consecuencia de las dificultades del erario de la ciudad, se vuelve a producir una drástica reducción de 
salarios, a cuyos efectos hubo de hacer frente el maestro Agustín Iranzo.

Otra fuente importante de ingresos de la capilla fueron las gratificaciones y recompensas que percibieron por acudir a las funciones extraordinarias, que no se contemplaban en los salarios ordinarios:

\section{TABLA DE GRATIFICACIONES $(1716-1800)^{26}$}

Asistencia al Te Deum

Procesión semana Santa

Composición de villancicos

Fiestas de la Concepción,

Santa Faz, Asunción y Corpus

Años del rey

Examinadores en

oposiciones

Nacimientos familia real

Asistencia a las misas en

fiestas
4 libs.

21 libs., 6 sdos., 8 dins.

De 3 a 8 libs.

12 libs.

12 libras.

De 6 a 20 libs.

10 libs.

Hasta 3 libs y 8 dins.

\section{La capilla de música como centro de enseñanza}

La capilla de música de San Nicolás fue el centro de la vida musical durante los siglos XVII al XVIII, período en el que la Iglesia fue principal protagonista de la vida cultural de la sociedad alicantina, puesto que de ella emanaba la mayor parte de las ceremonias y actos más solemnes. La Corona, la Iglesia y, en mucho menor medida la nobleza local, compartirản el mecenazgo de la música durante esta época, en la que, con no poca frecuencia, se enfrentaron por mantener su preeminencia no sólo política y social, sino también cultural.

La asimilación progresiva de las corrientes y movimientos propios del Siglo de las Luces tuvo también clara incidencia en el campo musical. Las modas europeas alcanzaron pronto a la Corte, pero no sólo a ella, puesto que la incoporación de maestros de capilla y músicos extranjeros contribuyó de forma decisiva a llevar a los templos y escenarios las nuevas formas musicales, y Alicante recibió ese influjo de la mano de maestros como Gabriel Aznar (1762-1772), Agustín Iranzo (1773-1781 y 1786-1804) y Vicente Torres (1781-1786).

Es importante destacar también el papel social que desempeñó la capilla. En primer lugar, la intervención de los poderes institucionales en la canalización de la cultura implicó que la capilla, bajo los auspicios capitulares, participara en todo tipo 
de actos sacros y civiles, y en ocasiones también en los puramente lúdico-festivos que organizó la ciudad. Igualmente, fue extraordinaria la labor realizada por los maestros en la enseñanza de músicos, cantores y niños del coro que se formaban al amparo de la colegial, constituyéndose en un foco cultural que permitió un notable nivel artístico. En segundo lugar, la aceptación por parte de la Iglesia de miembros seculares en la capilla abrió también las puertas a nuevas enseñanzas fuera de los círculos escolásticos. Pero, en definitiva, fue el cabildo municipal quien tuvo la última palabra en la gestión orgánica de la capilla.

Entre los siglos XVII y XVIII, la capilla de música funcionó como una autentica escuela. Se impartían todas las disciplinas (solfeo, canto, composición, polifonia, órgano, manejo de instrumentos), a leer, y escribir y a educar a los jóvenes que decidian seguir el camino de la música como profesión. No sólo se adiestraron en la música sacra, sino que estuvieron capacitados para participar en las funciones profanas.

Como institución dependiente del patronazgo municipal, la capilla desapareció en 1869, dejando tras de sí un rico archivo de partituras cuyo estudio servirá para calibrar con precisión el verdadero alcance de una labor continuada durante más de dos siglos. 


\section{NOTAS}

1.- Este artículo se basa principalmente en las conclusiones de nuestra Memoria de Licenciatura Música sacra y música profana en Alicante, La Capilla de Música de San Nicolás (siglos XVI-XVIII), dirigida por el Dr. D. Jesús Pradells Nadal y presentada el 31 de enero de 1994 en la Universidad de Alicante.

2.- La capilla de música intervino en el acto de la colocación de la primera piedra del pantano de Tibi en 1580, VIRAVENS PASTOR, R., El Pantano de Tibi, Ayto. de Alicante, 1972, p. 14. Del mismo modo, en 1598 se celebraron las exequias mortuorias de Felipe II en la parroquia de Santa Maria -entonces iglesia mayor- con la intervención de la capilla; en 1599 la ciudad preparó los festejos con motivo de las reales nupcias de Felipe III con Margarita de Austria, donde no faltaron las actuaciones musicales de la capilla de música, JOVER NICASIO, C., Reseña histórica de Alicante, Alicante, 1863, pp. 53-54.

3.- La Bula de proclamación fue recibida por el Consell de la ciudad el 24 de julio de 1600 . BENDICHO. V.. Chronica, cap. XXII. VIRAVENS PASTOR, R., Crónica de la liustre y Siempre Fiel Ciudad de Alicante, Alicante, 1876, red. de 1989, pp. 179-183.

4.- "La llustre Ciudad de Alicante como patrona de la iglesia colegial de San Nicolás desde su ercción y tiempo inmemorial, tiene establecida en ella la capilla de música que es parte principalisima de la soleminidad(...) y desde su origen paga los salrios de los músicos, gozando de sus provisiones dándoles sus títulos", A.M.A., Cabildos, Arm. 9, Lib. 70, ff. 136-138, memorial de 13 de enero de 1776.

5.- A.M.A. Estatutos para el Gobierno de la Ciudad de Alicante concedidos por S.C.R.M. del rey N.S.D. Carlos II, de 18 de diciembre de 1669, Arm. 5, Lib. 104, ff. 114-1 18.

6.- Composición de la capilla de música, período 1714-1723, A.M.A. Cabildos 1600-1869, Libros correspondientes al periodo consignado. Elaboración propia.

7.- Sobre la composición de la capilla de música, RUBIO, S., Historia de la Música Española, v. II, p. $13-48$.

8.- Fuente: A.M.A. Elaboración propia.

9.- A.M.A. Cabildos, Arm. 9, Lib. 4, f. 22, sesiỏn capitular extraordinaria de 14 de febrero de 1714.

10.- VIRAVENS PASTOR, R., Crónica de Alicante..., Alicante, 1876, p. 230.

11.- A.M.A. Cartas Recibidas, Arm. 9, Lib. 76, ff. 315v.-316, 20 de septiembre de 1781 y Cabildos, Arm. 9.,Lib. 76, ff. 362v.-365, de 19 de diciembre de 1781; Lib. 77, f. 197, de 1782.

12.- A.M.A. Cabildos, Arm. 9, Lib. 84, resolución capitular de 17 de agosto de 1789.

13.- La oposición para el magisterio se celebraba en la iglesia de San Nicolás: "Todos se dirigieron al templo tomando asiento los canónigos en los sitiales del ante coro de la parte de la derecha y los regidores en la parte de la izquierda. los examinadores se colocaron junto a la mesa preparada al efecto en la planicie entre el coro y el aitar mayor, dando la espalda a la puerta principal. El escribano ocupó su sitio junto a otra mesa colocada frente a los examinadores", A.M.A. Cabildos, Arm. 9, Lib. 68, ff. 4854. Elección definitiva de la plaza de maestro en favor de Agustin Iranzo, de 29 de enero de 1773. También vid.: PALENCIA SOLIVERES, A., Misica sacra y música profana..., Memoria de licenciatura inédita, Universidad de Alicante, 1994, pp. 77-79. 
14.- "... corrigiendo las faltas y omisiones de sus partes en debido iugar y tiempo, llevar el compás correspondiente con igualdad y disponer sus composiciones con estilo acompañado de verdadera ciencia", A.M.A. Cabildos, Arm. 9, Lib. 83, de 12 de octubre de 1788.

15.- A.M.A. Cabildos, Arm. 9, Lib. 124, Instrucción que deberá observar al tiempo de fijar los edictos para las oposiciones de maesiros de capilla, con fecha agosto de 1824 . Esencialmente no habían variado las disposiciones que se venian practicando durante el siglo XVIII. Perdurarian de esta forma hasta la disolución de la capilla en 1869 .

16.- Al maestro Vicente Torres (1784) se le negó la renta de 100 pesos por jubilación al no haber tomado las sagradas ordenes de clérigo, A.M.A., Arm. 9, Lib. 79, ff. 120v.-121 y 276-314.

17.- A.M.A. Cabildos, Arm. 9, Lib. 68, Obligaciones expuestas en el nombramiento del maestro Iranzo, enero de 1773.

18.- A.M.A., Cabildos, Arm. 9, período 1600-1700. A.H.M.E., Cabildos, Condiciones y Obligaciones de la iglesia Santa María de Elche, abril de 1785.

19.- A.M.A. Cabildos, Arm. 9. Lib. 97, ff. 78-78v.

20.- A.M.A. Cabildos. Arm. 9, Lib. 79, op. cit, 30 de abril de 1784.

21.- Fuente: A.M.A. Cabildos, periodo 1600-1869, eleboración propia.

22.- A.M.A. Cabildos, Arm. 9, Lib. 54, resolución capitular denegando la plaza de contralto a José Tormo por "no ponerse los hábitos" a pesar de tener buenas cualidades para el cargo. 14 de marzo de 1764 .

23.- El A.M.A. conserva un antiguo y valioso Arancel fechado en 1619 que regulaba la asistencia de la capilla a las festividades establecidas por la iglesia y el cabildo. Consta de 62 festividades y fiestas móviles en las que la presencia de los músicos era obligatoria. Aparecen los actos distribuidos entre los meses del affo, los desplazamientos a la parroquia de Santa María, al Ayuntamiento y a la iglesia de San Roque. Posteriormente, la capilla quedó sujeta a la última reforma del Arancel en 1790. Su contenido básico apenas sufrió modificaciones hasta el siglo XIX. A.M.A. Cabildos, Arm. 1, Lib. 7, ff. 112-113.

24.- DÍEZ BORQUE, J.M., Teatro y Fiesta en el Barroco, España e Iberoamérica, Sevilla, 1986, pp. 116. Algunas de las celebraciones más importantes que organizaba el cabildo quedaron recogidas en las fuentes historiográficas alicantinas como la Chrónica del P. BENDICHO, Alicante, 1640 (en los siglos XVI y XVII); para el siglo XVIII vid. Illice Ilustrada de los PP. MALTÉS y LÓPEZ, Alicante, 1991, también vid. VIRAVENS PASTOR, R., Crónica de la Ciudad de Alicante, Alicante, 1876.

25.- A.M.A. Libro de Ordenes de Propios y Arbitrios, Arm. 13, Lib. 2, ff. 61 v., período 1760-71; Asientos de Propios, Arm. 10, Caja 1, Lib. 92, ff. 10-17.

26.- Fuente: A.M.A. Cabildos, Arm. 9, volúmenes correspondientes a los años consignados. Elaboración propia. 